\title{
Consumer Preferences for Dark Chocolate Products Fortified with Spirulina Platensis Using Analytical Hierarchy Process Method
}

\author{
Gisela Karina Asti and Nurfitri Ekantari* \\ Fisheries Department, University of Gadjah Mada, Yogyakarta
}

\begin{abstract}
Abatract. Chocolate is a product made from cocoa (Theobroma cacao) beans and fat which is very popular because of its taste and nutrition. Dark chocolate has health benefits because of it's contains antioxidants in the form of phenols and flavonoids. In previous study, the addition of $\beta$-carotene extract from $S$. platensis with a dose of $0.372 \%$ to dark chocolate products was aimed to fulfilling energy intake and vitamin A needs. Thus, it's important to know the consumer preferences for dark chocolate products fortified with $S$. platensis. This study aimed to determine the priority weight of the attributes for consumers and measure consumer preferences for dark chocolate products fortified with $S$. platensis. This study used the Analytical Hierarchy Process method. Data were collected by distributing questionnaires to 100 respondents unskilled who representing the population level in Yogyakarta, using purposive random sampling. The results showed that the priority attributes of consumer in choosing dark chocolate products fortified with S. platensis are taste, sub-attribute of bitter taste $(47.8 \%)$, price, sub-attribute of low price $(53.3 \%)$, product benefits, subattribute of nutritional benefit (38.2\%), flavor, sub-attribute of sweet flavor (64.2\%), texture, sub-attribute of smooth texture (57.7\%), aroma, sub-attribute of typical chocolate aroma (72.8\%), and packaging, sub-attribute of packaging 2 (Lindt packaging) $(25.8 \%)$. Meanwhile, the choice of dark chocolate products according to the consumer preferences is dark chocolate product fortified with S. platensis with priority weight of $55.8 \%$.
\end{abstract}

\section{Introduction}

Spirulina platensis is a blue-green microalga classified as single-celled cyanobacteria with spiral body shape [1]. Spirulina has good protein, essential fatty acids, vitamins, minerals, chlorophyll, and phycocyanin used as a functional food. Spirulina is often referred to as a nutraceutical ingredient because it has phytonutrients (phycocyanin, carotene, and xanthophylls), gamma-linolenic acid (GLA) galacto-lipids, sulfo-lipids, chlorophyll and minerals [2]. Besides, phycocyanin, phycocyanobilin, and allophycocyanin compounds in Spirulina biomass are known to function as effective anticancer, antibacterial, antifungal, and antiviral agents [3]. High content of phycocyanin pigment shows antioxidant characteristic, which functions as an inflammatory, inhibits tumor necrosis and protects nerve cells [4]. Besides, spirulina also contains high carotenoids, especially $\beta$-carotene [5].

$\beta$-carotene is one of the carotenoids that can be converted into vitamin $\mathrm{A}$ in the body. According to [6], $\beta$-carotene compounds are unsaturated because, in their structure, they contain double bonds which result in changes leading to damage. The stability of $\beta$-carotene is strongly influenced by oxidation, heat, and light. One way to protect and deal with damage to $\beta$-carotene compounds is by forming carotenoid microencapsulation. Encapsulation is the process of coating an active compound with another material so

\footnotetext{
*Corresponding author : nurfitri@ugm.ac.id
} 
that it can protect the active compound while releasing it into its solubility [7]. The Spirulina platensis nanocapsule product can be fortified in a food product to improve the fulfillment of vitamin A requirements.

The fortification of chocolate products with Spirulina platensis nanocapsules was carried out by [8], showing the most preferred product was chocolate with the addition of spirulina at a dose of $5 \%$ with a $\beta$ carotene content of $70.33 \mu \mathrm{g} / \mathrm{gram}$. Meanwhile, the chocolate without spirulina had a lower $\beta$-carotene content of $3.43 \mu \mathrm{g} / \mathrm{gram}$. These results indicate several weaknesses, such as the fishy odor, grainy texture, low gloss, easy fat bloom development, and color fading under light and metal exposure. The weaknesses were then improved by [9] who found that the best product combination, according to the consumer preference, was the dark chocolate with a combined ratio of cocoa mass and cocoa fat of 40:30, with a tempering temperature of $35^{\circ} \mathrm{C}$, added with Spirulina platensis nanocapsules of $0.372 \%$ containing $22 \mathrm{mg} / \mathrm{g}$ carotenoid. Chocolate added with a carotenoid extract from Spirulina platensis can meet the needs of energy and vitamin A better than commercial chocolate bars. Consuming 53.6 grams of dark chocolate with the addition of Spirulina platensis results in 270 calories, which meets the daily requirement of vitamin A (82\%). Meanwhile, consumers need to consume 336 grams of dark chocolate without the addition of Spirulina to meet the daily vitamin A needs [9]. Therefore, with the fortification of chocolate products with Spirulina platensis, the consumers are expected to be able to choose and consume chocolate bars according to the nutritional values.

Each consumer has different criteria for the desired product according to their preferences. Consumer preference is the choice of whether a person likes a product or service. Consumer preferences indicate consumer preferences for a variety of available products [10]. Understanding consumer preferences aims to determine the marketing strategy on an ongoing basis so that the goods or services marketed are following the consumer demand. The variety of chocolate products on the market makes consumers more selective in choosing products, thus producers need to examine consumer preferences. One factor in choosing a product is the product attributes, which are the components of products that can meet the needs and desires of consumers. The benefits of a product are included in product attributes [10]. The attributes used in choosing chocolate products are taste (sweetness level and chocolate flavor), aroma, product variation, shape, size, food safety, milk content, packaging, durability, and prices [11]. On the other hand, attributes in choosing chocolate products are health information, sensory, and product history [12].

Decision making to determine consumer preferences for a product becomes difficult concerning the limitations of data, information, and the high number of criteria for product development. One analysis that can be used to determine consumer preferences for a product is the Analytical Hierarchy Process (AHP), which is one of the decision-making methods often used to prioritize various alternatives/choices that are complex or multi-criteria [13]. The application used to assist decision making with the Analytical Hierarchy Process is the application of expert choice v11. Therefore, the results of this analysis can be used to obtain the attributes of a product most preferred by consumers. Moreover, the result can be used to learn the factors that influence consumer preferences for a product and to determine consumer preferences for dark chocolate products fortified with Spirulina platensis so as to facilitate producers in marketing and developing the products.

\section{Materials and methods}

The ingredients used in making chocolate bars were fermented cocoa beans from cocoa farmers in Kalibawang, refined sugar (Point), cocoa butter (Tulip), vegetable lecithin (Point), vanilla (Koepoe Koepoe), baking soda (Koepoe Koepoe), mineral water, and Spirulina platensis nanocapsules with gum arab and WPC (Whey Protein Concentrate) encapsulants was the research result of [14] from the Fish Processing Technology Laboratory, Department of Fisheries, Universitas Gadjah Mada, D.I. Yogyakarta, Indonesia. The materials tested in this study were dark chocolate bars with and without the addition of Spirulina platensis carotenoid nanocapsules at a dose of $0.372 \%$.

The method used in this study was the Analytical Hierarchy Process (AHP) to determine consumer preferences for dark chocolate products fortified with Spirulina platensis. The stages of the study are shown in Figure 1. 


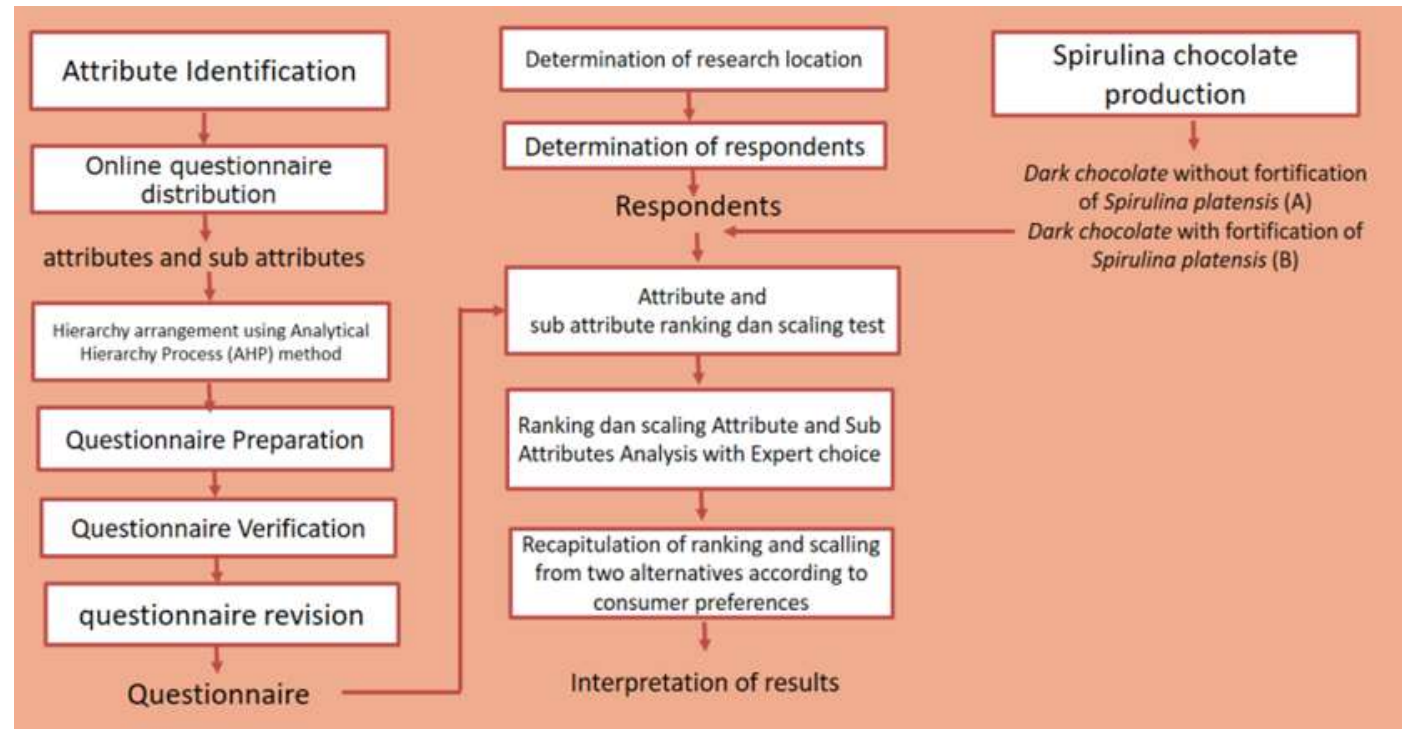

Fig. 1. Stages of study

1. Attribute identification

At this stage, online questionnaires were distributed via Google forms on social media including LINE, WhatsApp, and Instagram applications to obtain the attributes chosen by consumers in buying or consuming chocolate products. The identification of sub-attributes was done by a literature study.

2. Determining attribute and sub-attribute

Attributes and sub-attributes were determined based on the results of the distribution of online questionnaires and literature studies. The attributes chosen by most online questionnaire respondents were selected as the attributes of this study. Sub-attributes were selected based on the results of the literature studies that are relevant to this study.

3. Hierarchy arrangement using Analytical Hierarchy Process (AHP) method

The hierarchy was arranged starting from the highest level, which is the goal, followed by the second level, which is the criteria. The third level is the sub-criteria, and the last level is an alternative. The compilation of a hierarchy shows the relationship between attributes and sub-attributes. It also shows the relationship between sub-attributes and their alternatives.

4. The preparation and verification of the questionnaires for AHP testing

The questionnaire is a primary data collection tool with a survey method to obtain respondents' opinions. Questionnaires can be used to obtain personal information such as attitudes, opinions, hopes, and desires of respondents [15]. The research questionnaires were distributed to obtain data on the attributes considered by consumers in buying dark chocolate products and alternative products that were acceptable to consumers. The preparation of the questionnaire was carried out by dividing the questionnaire into two parts, namely:

a. The first part contained the personal data of the panelists who filled out the questionnaire. The personal data included name, age, gender, occupation, average monthly expenses, test location, and test date.

b. The second part contained the Analytical Hierarchy Process test. Analytical Hierarchy Process testing questionnaire was preceded by AHP testing instructions, followed by weighting each of the attributes selected by consumers in buying dark chocolate products using pairwise comparisons using a rating scale of 1 to 9 according to [16]. The first comparison was to compare one attribute with another attribute, for example comparing the taste with texture, aroma, product benefits, price, packaging, and flavor, as well as comparing other attributes by selecting a scale of values ranging from 1 to 9 . The second comparison was done by comparing one sub-attribute with another sub-attribute, for example, comparing sub-attribute of bitter taste with acidic and astringent taste, as well as comparing other sub-attributes by choosing a scale of values ranging from 1 to 9 . Finally, the panelists were asked to rate sub-attributes by comparing them in both alternatives. The panelists were asked to choose the products (A and B) with consideration of certain sub-attributes. At this stage, the panelists were given information about product A, which was dark chocolate without Spirulina platensis, and product B, which was dark chocolate with Spirulina platensis. The AHP questionnaires were verified by requesting an assessment by an expert (expert judgment) to minimize the level of 
weaknesses and errors of the questionnaire. Questionnaire verification was carried out during the research progress seminar.

5. Determination of the research location

The research location was determined based on the results of the distribution of online questionnaires in this research, in which $49 \%$ of respondents chose a minimarket and $40 \%$ of respondents chose supermarkets as a place to buy chocolate bars. The respondents who liked chocolate were mostly students. The questionnaire distribution was carried out at the campus of the Department of Fisheries, Faculty of Agriculture, UGM, Indomaret Point, Hypermart Hartono Mall, Transmart Carrefour, and Miu Miu Thai Tea Perumnas branch.

6. Determination of the respondents

The respondents were determined by purposive sampling method. The purposive sampling method is a sampling that is carried out with the assumption that the sample has the information needed for research [17]. Selected respondents were 100 unskilled respondents with the condition that respondents were willing to fill out the questionnaires, likes chocolate bar products and often consuming chocolate bar products.

7. The making of chocolate with spirulina

The chocolate bars made were dark chocolate without Spirulina platensis and dark chocolate fortified with Spirulina platensis.

8. Weighting test of attribute and sub-attribute

The weighting test of attribute and sub-attribute and paired comparison testing were conducted on 100 respondents to see whether the questionnaire tested was appropriate and capable of producing valid and representative data. The weighting test was carried out with the following steps:

a. Element comparisons (comparative judgement)

Paired element comparisons are important stages in the analytic hierarchy process because they will affect the priority of the attributes of the product tested. Pairing comparisons were carried out by comparing all elements in paired forms for each sub-system of the hierarchy and then transformed in the form of a matrix for numerical analysis. The numerical value imposed for comparison was obtained from a comparison scale made by [16], which is shown in Table 1.

Table 1. The fundamental scale of absolute numbers [16]

\begin{tabular}{|l|l|l|}
\hline $\begin{array}{l}\text { Intensity of } \\
\text { Importance }\end{array}$ & Definition & Explanation \\
\hline 1 & Equal Importance & Two activities contribute equally to the objective \\
\hline 3 & Moderate Importance & $\begin{array}{l}\text { Experience and judgement slightly favor one activity } \\
\text { over another }\end{array}$ \\
\hline 5 & Strong Importance & $\begin{array}{l}\text { Experience and judgement strongly favor one activity } \\
\text { over another }\end{array}$ \\
\hline 7 & $\begin{array}{l}\text { Demonstrated } \\
\text { Importance }\end{array}$ & $\begin{array}{l}\text { An activity is favored very strongly over another; its } \\
\text { dominance demonstrated in practice }\end{array}$ \\
\hline 9 & Extreme Importance & $\begin{array}{l}\text { The evidence favoring one activity over another is of } \\
\text { the highest possible order of affirmation }\end{array}$ \\
\hline $2,4,6,8$ & Middle value & $\begin{array}{l}\text { Given if there are doubtful judgments between adjacent } \\
\text { judgments }\end{array}$ \\
\hline Reciprocals & $\mathrm{a}_{\mathrm{ji}}=1 / \mathrm{a}_{\mathrm{ji}}$ & \multicolumn{2}{|l}{} \\
\hline
\end{tabular}

b. Calculating elements priority weight (synthesis of priority)

After being transformed in the form of a matrix, the data were then weighed and summed to produce a single number that shows the priority of each element.

c. Measuring consistency (logical consistency)

It is very important to identify the level of consistency in decision making. The more factors that must be considered, the more difficult it is to maintain consistency. The consistency index is used to measure the consistency of decision making in comparing elements in the assessment matrix. The consistency value must be $10 \%$ or less. Otherwise, it might be rather random so that it needs to be fixed. Furthermore, the consistent index is transferred according to the order or size of the matrix into a consistency ratio (CR/Consistency Ratio). The consistency was calculated based on the value of the Consistency Ratio (CR) obtained from a comparison between the Consistency Index and the Random Index. 
d. Calculating global priority value of sub-attribute

Global priority values can be calculated by multiplying the weights of each sub-attribute against its parent attribute.

9. Analysis of attribute and sub-attribute weighting using AHP

The results of attributes and sub-attributes weighting on the AHP questionnaire were analyzed using the help of Expert choice v11 ware.

10. Recapitulation of the weights of the two alternatives according to consumer preferences

Weight recapitulation was done with the help of Expert choice v11 software.

11. Result interpretation

The results of the interpretation are displayed in graphs, and the purpose of the graphs is described to obtain the final result related to the consumer preferences for dark chocolate products fortified with Spirulina platensis and the attributes and sub-attributes which are most desirable to consumers.

\section{Results and discussion}

\subsection{Attribute identification}

Attribute identification was conducted by distributing questionnaires online through social media to find out the attributes that were chosen by consumers in buying or consuming chocolate bars. The questionnaires used were in the form of Google forms and distributed for three weeks. There s were 239 respondents who filled out online questionnaires, and as many as 90 respondents liked the dark chocolate bar. Data results are shown in Table 2 .

Table 2. Data of online questionnaire respondents

\begin{tabular}{|l|l|l|}
\hline No & Respondent data & Amount (\%) \\
\hline 1 & Age & \multicolumn{1}{l|}{} \\
\hline & $12-16$ & 0 \\
\hline & $17-25$ & 73 \\
\hline & $26-35$ & 15 \\
\hline & $36-45$ & 3 \\
\hline & $46-55$ & 5 \\
\hline & $56-65$ & 4 \\
\hline 2 & Gender & \multicolumn{2}{|l|}{} \\
\hline & Male & 42 \\
\hline & Female & 58 \\
\hline 3 & Occupation & \\
\hline & College students & 51,1 \\
\hline & Employee & 3 \\
\hline & Entrepreneur & 7,7 \\
\hline & Civil servant & 4,4 \\
\hline & Student & 2,2 \\
\hline & Teacher & 1,11 \\
\hline & Housewife & 1,11 \\
\hline & Others & 2,5 \\
\hline
\end{tabular}

Respondents who filled out online questionnaires were dominated by 17-25-year-old respondents (73\%), female $(58 \%)$, and college students $(51,1 \%)$. The results of the online questionnaire data regarding dark chocolate bars are shown in Table 3. 
Table 3. Online questionnaire data on dark chocolate bars

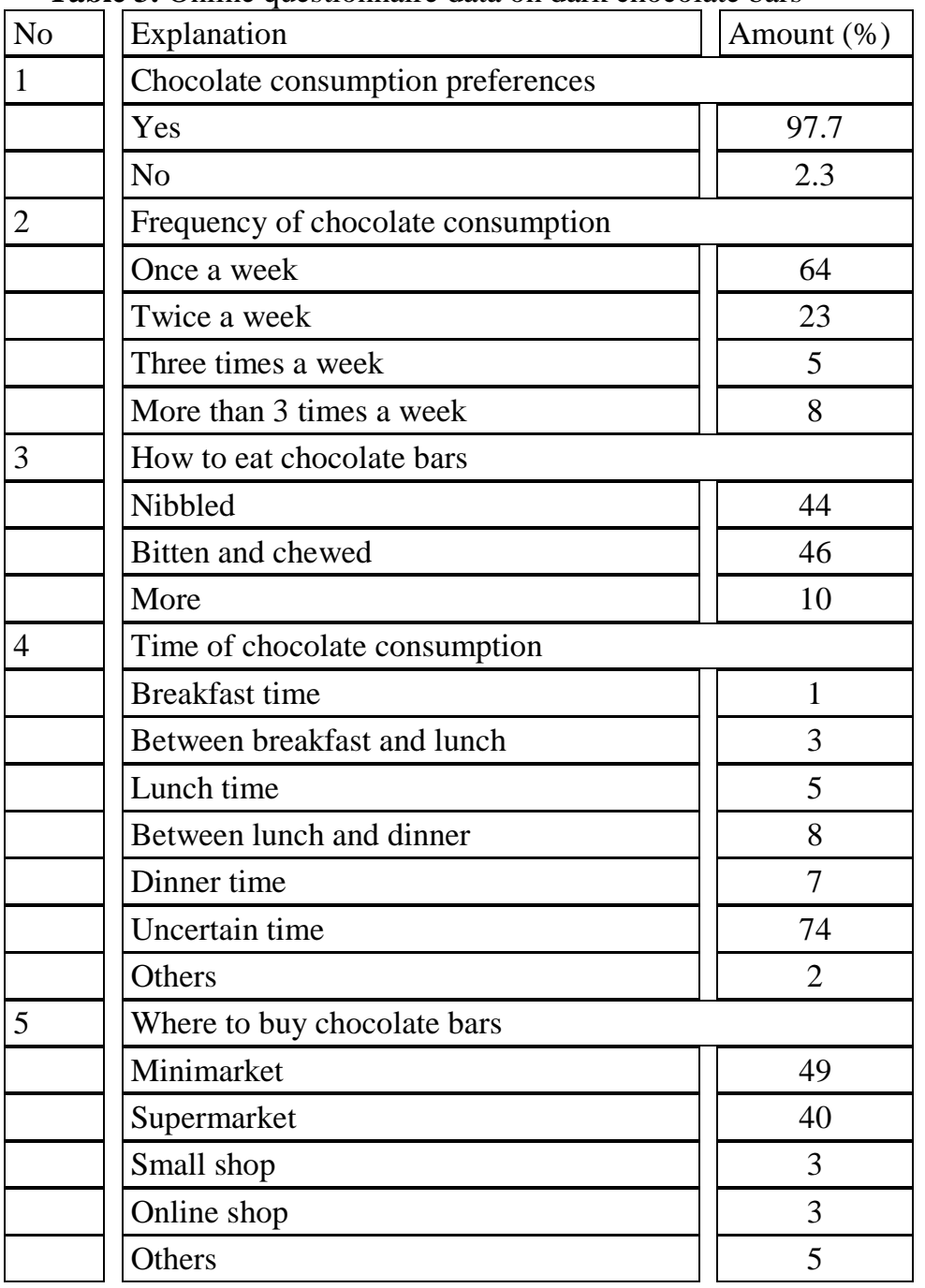

This data showed that $88 \%$ of respondents liked dark chocolate bars more than others and $64 \%$ of respondents consumed chocolate once a week. Based on the respondent's way of consuming chocolate bars, $46 \%$ of respondents preferred to consume chocolate by bitten and chewed more than other ways. Meanwhile, according to the time of consuming chocolate, $74 \%$ of respondents eat chocolate at an uncertain time. Mostly, the respondents buy chocolate at a convenience store (49\%). A diagram of the main factors in buying dark chocolate bars is shown in Figure 2. 


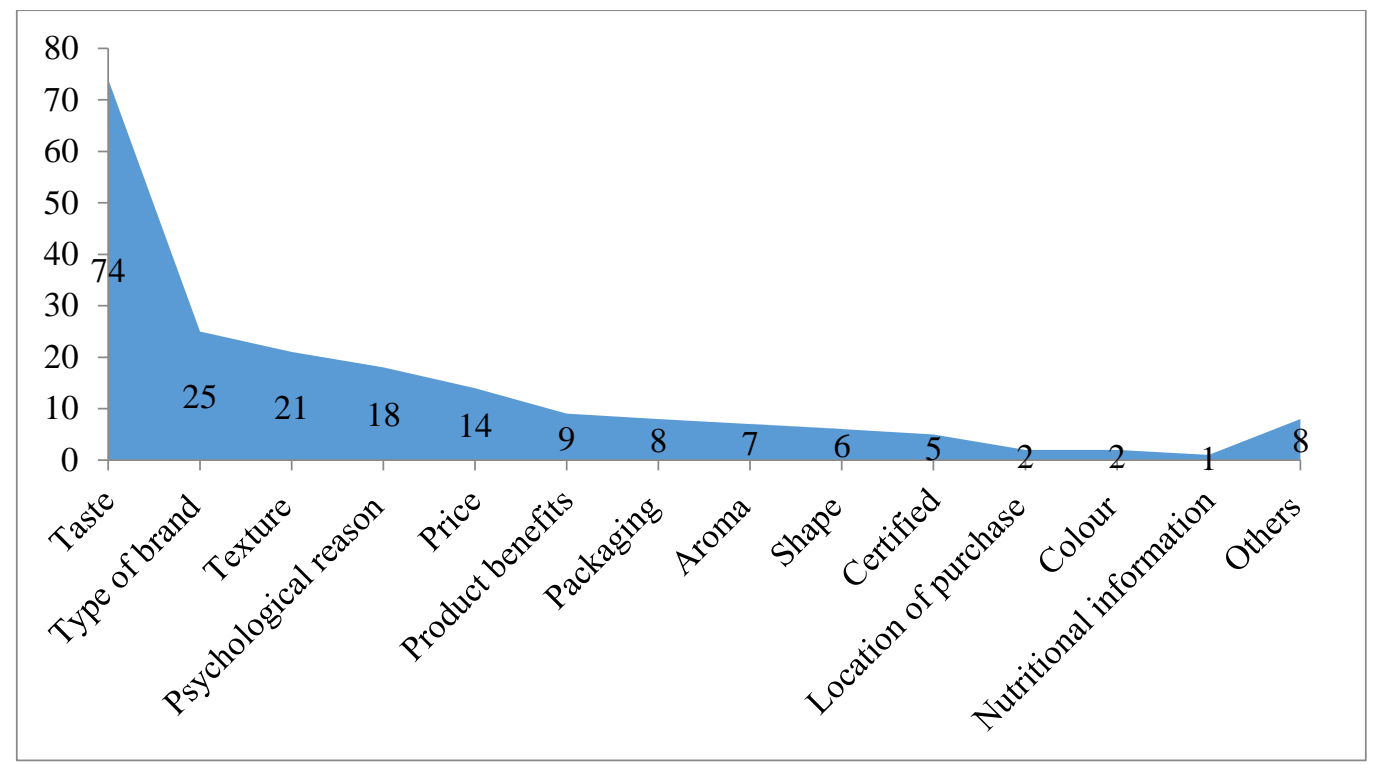

Fig. 2. Main factors in buying dark chocolate bars

The respondents were asked to choose several factors that become the reason to consume chocolate bars. They were allowed to choose more than one factor. Some of the main factors chosen by the respondents in buying chocolate bars included taste $(74 \%)$, brand $(25 \%)$, texture $(21 \%)$, psychological reasons $(18 \%)$, price $(14 \%)$, product benefits $(9 \%)$, packaging $(8 \%)$, aroma (7\%), and so on. The main factor that had the highest value was the attribute chosen in the preparation of the AHP questionnaire. From the results of the study, seven of the highest attributes were taken as the main factors consumers in buying chocolate products. The attributes chosen are taste, texture, price, product benefits, packaging, aroma and flavor. Meanwhile, the type of brand was not chosen because dark chocolate products fortified with S.platensis did not have a brand while psychological reason was a sub attribute of product benefits.

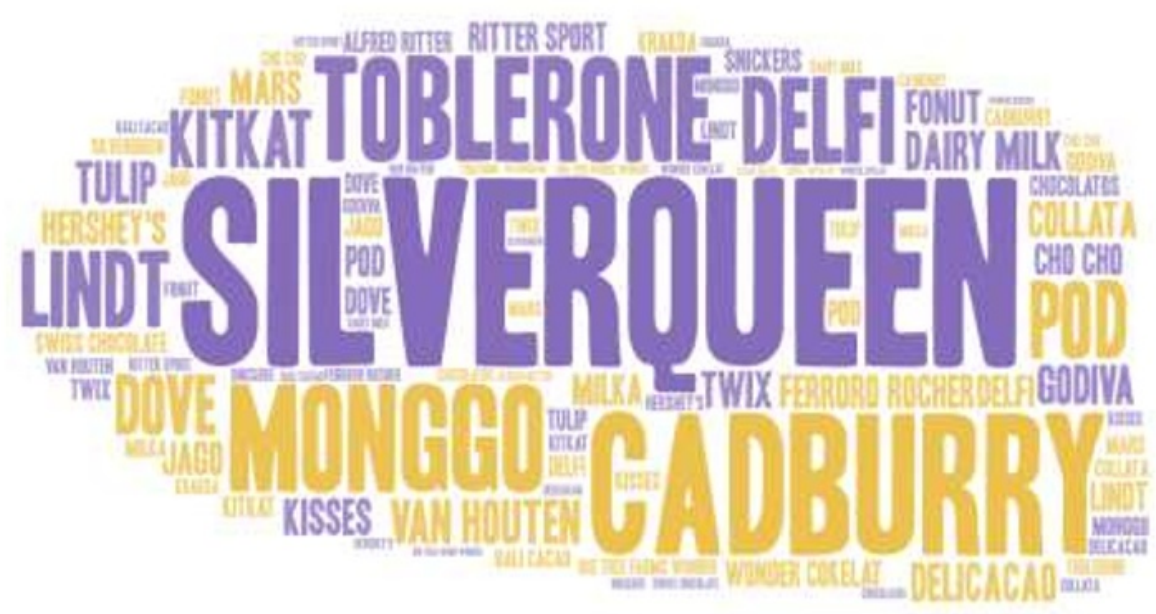

Fig. 3a. The brand of chocolate bars that are known 


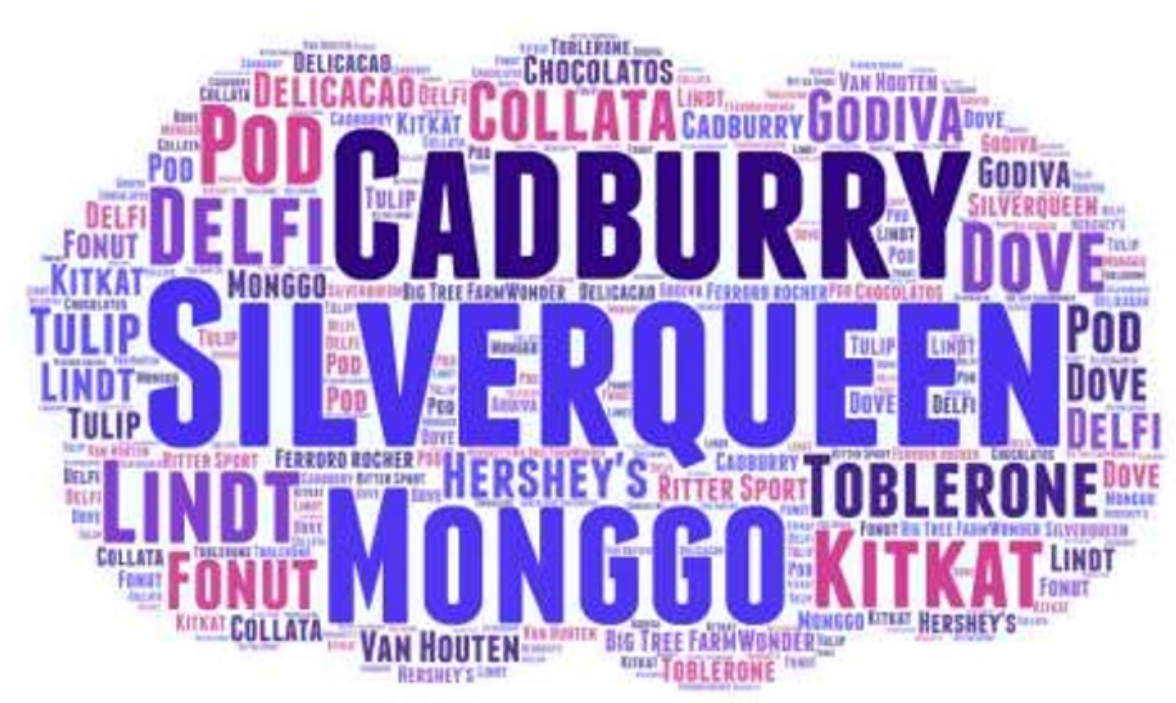

Fig. 3b. The brand of chocolate bars that are consumed

The brand of chocolate bars that are known and consumed are shown in Figure 3a and Figure 3b. The word cloud data illustrate that the brands of chocolate bars known and consumed by the customers are approximately the same, comprising Silverqueen, Cadburry, Monggo, Toblerone, and others. The results of the online questionnaire data regarding Spirulina are shown in Table 4.

Table 4. Online questionnaire data regarding the respondent knowledge about spirulina

\begin{tabular}{|l|l|c|}
\hline No & Explanation & Amount (\%) \\
\hline 1 & Does the respondent know what spirulina is? & 15 \\
\hline & Yes & 39 \\
\hline & No & 46 \\
\hline & Maybe & \multicolumn{2}{|}{20} \\
\hline 2 & Has the respondent ever consumed spirulina? & 80 \\
\hline & Yes & \\
\hline & No
\end{tabular}

There were $46 \%$ of the respondents already knowing spirulina. Most respondents answered that spirulina is a micro-algae or green-blue algae serving as additional food for fish and as additional ingredients for cosmetics and medicines. Meanwhile, $20 \%$ of the respondents said that they had consumed spirulina in the form of ice cream, pills or capsule supplements, face masks, and cookies.

\subsection{Attribute and sub-attribute of dark chocolate products}

Attributes taken from the results of the distribution of online questionnaires that have the highest weight are considered important and relevant in making decisions to buy chocolate bars fortified with Spirulina platensis. The attributes and sub-attributes of the dark chocolate product are shown in Figure 5. 


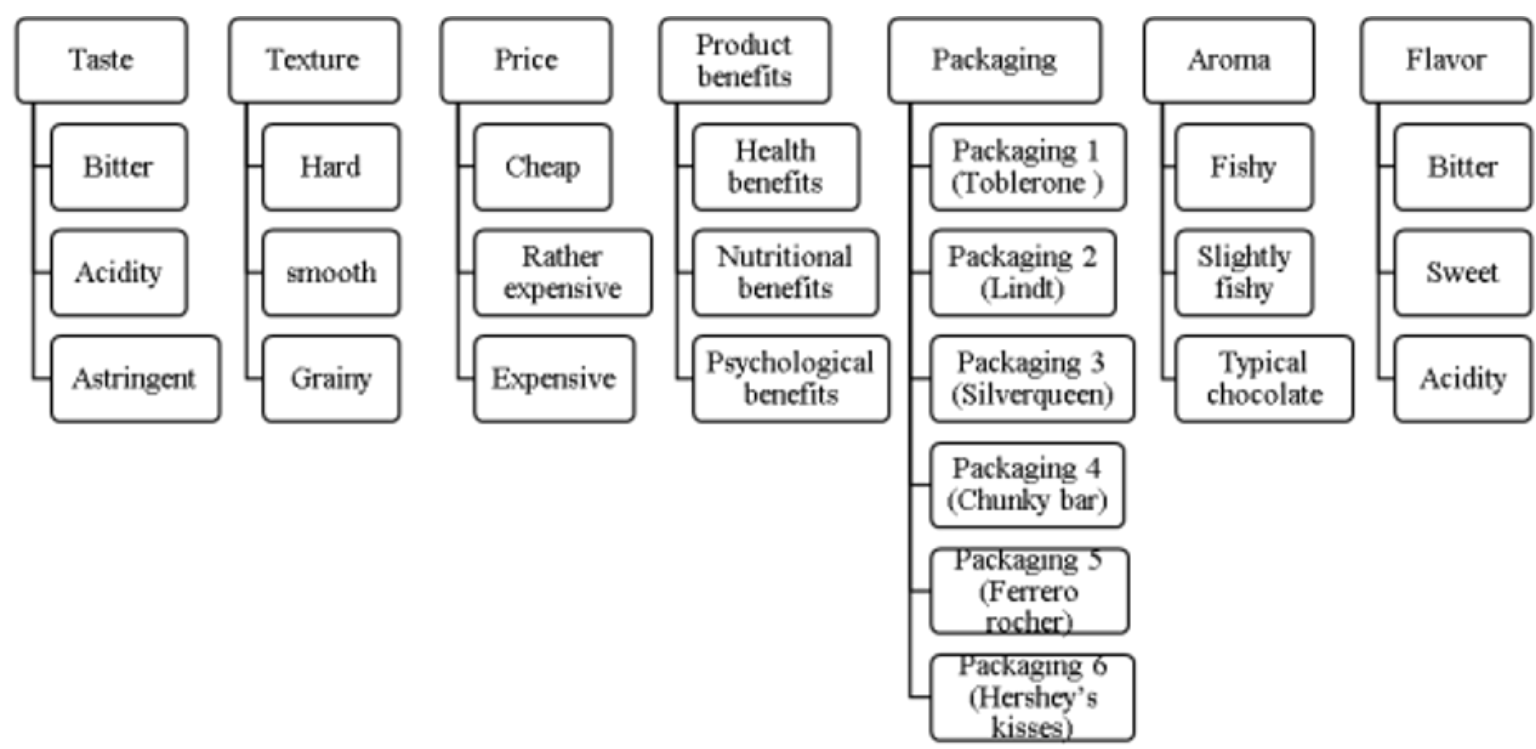

Fig. 5. Attributes and sub-attributes of dark chocolate products

The factors considered in buying chocolate bars, from high to low weight, included taste, brand, texture, psychological reasons, price, product benefits, packaging, aroma, shape, certification, location of purchase, color, nutritional information, and others. The brand factor was not used in the study because it did not match the product to be sold. Psychological reasons were combined in the product benefits attribute to be a subattribute of psychological benefits. Shape, certification, location of purchase, color, nutritional information, and others were not selected as attributes because they had a small amount of value. The flavor was added to the attribute because the flavor is a combination of the sense of taste and sense of smell (odor) so that it affects consumers' judgment in choosing a product.

1. Attribute of taste

Taste is a form of unity of five kinds of senses, including taste, smell, touch, sight, and hearing [18]. Taste attributes have three sub-attributes, consisting of bitter, acidic, and astringent taste. In chocolate, two compounds play a role in giving a bitter taste, including theobromine and caffeine [19]. Besides theobromine and caffeine, the bitter taste in chocolate is due to the presence of polyphenols and flavonoids in cocoa beans. The acidic taste is caused by the acid content in cocoa beans during processing, especially during roasting and conching, which has not completely evaporated. Meanwhile, the astringent taste in chocolate is caused by the content of anthocyanin, which is partially decomposed during the fermentation process [20].

2. Attribute of texture

Texture is a pressure sensor that can be observed with mouth (when bitten, chewed, and swallowed) or by touching using fingers [21]. In this research, texture attribute has three sub-attributes, there are smooth, grainy, and hard. The level of smoothness and hardness in dark chocolate is obtained during conching and tempering processes and is also influenced by the amount of cocoa butter used. According to the study of [8], the texture of dark chocolate fortified with Spirulina platensis was grainy.

3. Attribute of price

Price is the amount of money that consumers must pay to get a product or service [22]. The price attribute has three sub-attributes, which are cheap, rather expensive and expensive. This category is made to map consumers who prefer to buy dark chocolate products fortified with Spirulina platensis at low prices, rather expensive or expensive if they know the benefits contained therein. The selling price of dark chocolate products fortified with Spirulina platensis is IDR 25,000.

4. Attribute of product benefits

Product benefits are the ability of the product or service to meet consumer needs. The more benefits or uses a product has, the more motivated consumers will be to buy the product [23]. Attributes of product benefits in dark chocolate products have three sub-attributes, namely health benefits, nutritional benefits, and psychological benefits.

5. Attribute of packaging

Packaging is a case of an item to make it safe, attractive, and appealing. Packaging is also a medium of communication between producers and prospective consumers so that it must contain information that must be known by the consumers. The more complete the information contained in the packaging makes the 
buyer more aware and more confident about products sold [24]. The packaging attributes have six subattributes including packaging 1 (Toblerone packaging), packaging 2 (Lindt packaging), packaging 3 (Silverqueen packaging), packaging 4 (Chunky bar packaging), packaging 5 (Ferrero rocher packaging) and packaging 6 (Hershey's Kisses packaging).

6. Attribute of aroma

Aroma is a scent caused by chemical stimuli that are smelled by olfactory nerves that are in the nasal cavity [8]. Aroma attributes have three sub-attributes, including fishy, slightly fishy, and typical chocolate. Fishy and slightly fishy attributes were determined based on the research by [8], reporting that chocolate fortified with Spirulina platensis had a fishy/leaf/grassy odor due to the strong aroma of Spirulina platensis. Meanwhile, the distinctive aroma of chocolate is obtained from the compounds contained in cocoa beans. These compounds are formed during the process of preparing seeds, especially during the fermentation and drying process. During the screening, the taste-forming compounds are reacting with each other to produce volatile and typical aromatic components of chocolate [25].

7. Attribute of flavor

Flavor is a complex component because it can be volatile and non-volatile, and it can change due to time and processing conditions. Flavor is formed as a result of the combined experiences and sensations we receive from the characteristics of the ingredients [26]. The flavor attributes have three sub-attributes, including bitter, sweet, and acidic taste. These attributes were obtained from the QDA test results of dark chocolate products fortified with Spirulina platensis.

\subsection{Respondents' characteristics of AHP weighting test}

There were 100 respondents obtained from the results of questionnaires distribution. Data of AHP weighting test respondents are shown in Table 5.

Table 5. Test of AHP weights

\begin{tabular}{|l|l|l|}
\hline No & Respondent data & Amount (\%) \\
\hline 1 & Age & \multicolumn{2}{|l|}{} \\
\hline & $17-25$ & 57 \\
\hline & $26-35$ & 24 \\
\hline & $36-45$ & 10 \\
\hline & $46-55$ & 6 \\
\hline & $56-65$ & 3 \\
\hline & Gender & \\
\hline & Male & 47 \\
\hline 3 & Female & 53 \\
\hline & Occupation & \\
\hline & College student & 42 \\
\hline & Employee & 23 \\
\hline & Entrepreneur & 5 \\
\hline & Civil servant & 25 \\
\hline & Teacher & 4 \\
\hline & Private employee & 1 \\
\hline
\end{tabular}

The proportion of AHP testing respondents was dominated by 17-25-year-old respondents (57\%), female respondents $(53 \%)$ and students $(42 \%)$.

\subsection{Hierarchy arrangement}

The hierarchy was arranged from the top level, which was the purpose of AHP testing. The purpose was to determine consumer preferences and the most preferred attributes of dark chocolate products fortified with Spirulina platensis. The attributes and sub-attributes of the identification results then were arranged on the next level, as criteria and sub-criteria. Finally, the alternatives were arranged, which in this study, two alternatives 
were used (dark chocolate with and without fortification of Spirulina platensis). The results of hierarchical arrangement are shown in Figure 7.

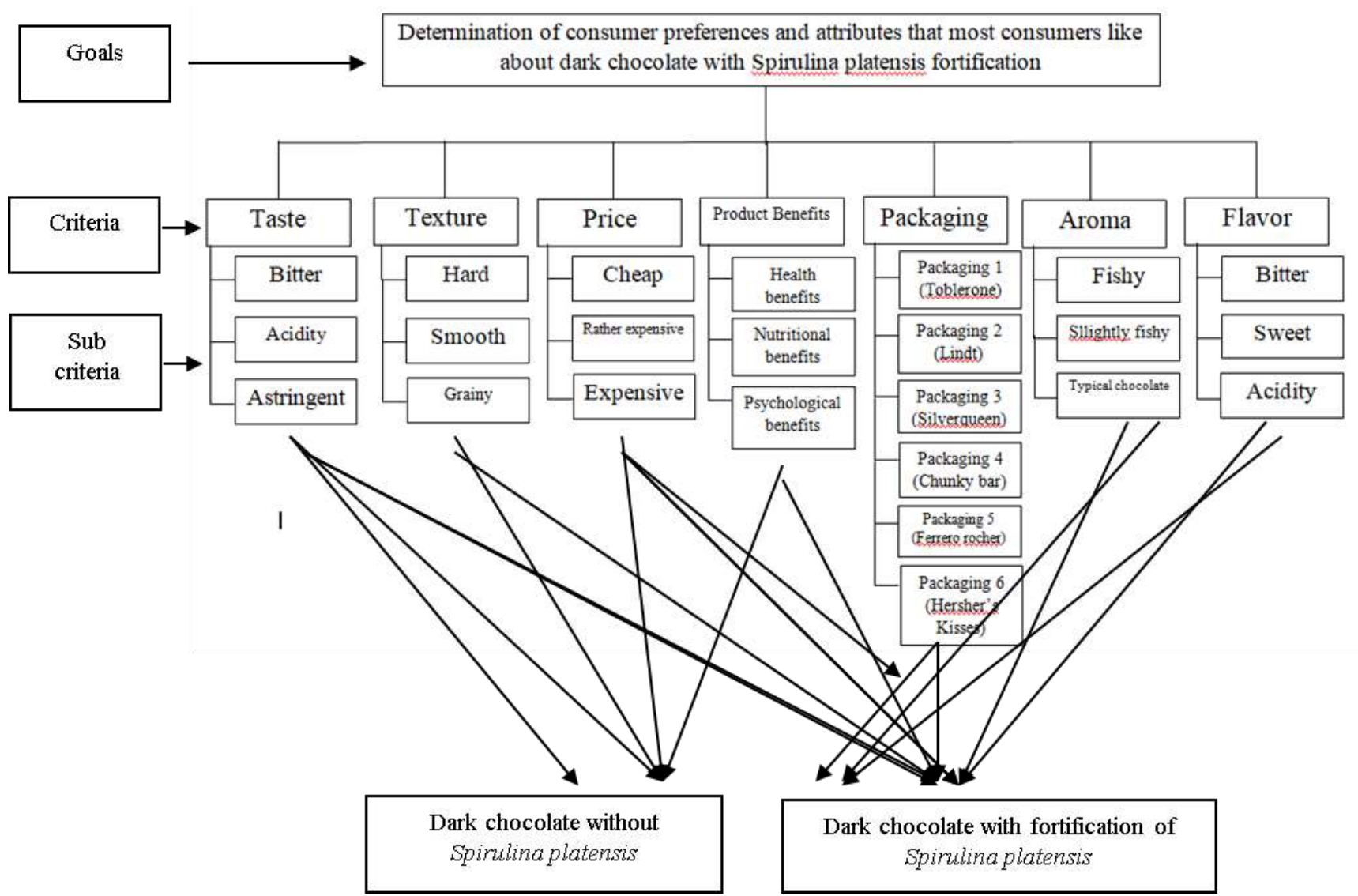

Fig. 7. Hierarchy of the study on the consumer preference for dark chocolate

\subsection{Analysis of the product attributes on the consumer preference}

In the Analytical Hierarchy Process test, the data from the pair comparison matrix and priority weights of various attributes were obtained. From the questionnaires distribution in the Analytical Hierarchy Process test, data of priority weight of the attributes were obtained to be processed using the Expert choice v11 were shown in Table 6.

Table 6. Priority weight of the attributes using expert choice

\begin{tabular}{|c|c|c|}
\hline No & Attribute & Priority value (\%) \\
\hline 1 & Taste & 19.1 \\
\hline 2 & Price & 18.5 \\
\hline 3 & Products benefit & 17.1 \\
\hline 4 & Flavor & 16.9 \\
\hline 5 & Texture & 10.1 \\
\hline 6 & Aroma & 10 \\
\hline 7 & Packaging & 8.3 \\
\hline
\end{tabular}

The results of the attribute analysis showed that the taste attribute was the highest indicated by the priority value of $19.1 \%$. This attribute will be the most considered attribute for consumers of dark chocolate while the packaging attribute was the lowest considered attribute for consumers of dark chocolate.

\subsection{Analysis of the product sub-attributes on the consumer preference}


From the questionnaires distribution in the Analytical Hierarchy Process test, data of priority weight of the sub-attributes were obtained to be processed using the Expert choice v11 software shown in Table 7.

Table 7. Priority weight of the sub-attributes using expert choice

\begin{tabular}{|c|c|c|c|}
\hline No & Attribute & Sub-Attribute & Priority weight $(\%)$ \\
\hline \multirow{4}{*}{1} & \multirow{3}{*}{ Taste } & Biter & 47.8 \\
\hline & & Acidic & 31.6 \\
\hline & & Astringent & 20.7 \\
\hline & & Cheap & 53.3 \\
\hline \multirow{3}{*}{2} & \multirow{2}{*}{ Price } & Rather expensive & 33.1 \\
\hline & & Expensive & 13.5 \\
\hline & & Health benefit & 37.1 \\
\hline \multirow{2}{*}{3} & \multirow{2}{*}{$\begin{array}{l}\text { Products } \\
\text { benefit }\end{array}$} & Nutritional benefit & 38.2 \\
\hline & & Physiological benefit & 24.6 \\
\hline & & Bitter & 19.2 \\
\hline \multirow{2}{*}{4} & \multirow{2}{*}{ Flavor } & Sweet & 64.2 \\
\hline & & Acidic & 16.6 \\
\hline & & Hard & 25.9 \\
\hline \multirow{2}{*}{5} & \multirow{2}{*}{ Texture } & Smooth & 57.7 \\
\hline & & Grainy/greasy & 16.5 \\
\hline & & Fishy & 10 \\
\hline \multirow{2}{*}{6} & \multirow{2}{*}{ Aroma } & Slightly fishy & 17.2 \\
\hline & & Typical chocolate & 72.8 \\
\hline \multirow{6}{*}{7} & \multirow{6}{*}{ Packaging } & Packaging 1 (Toblerone) & 16.8 \\
\hline & & Packaging 2 (Lindt) & 25.8 \\
\hline & & Packaging 3 (Silverqueen) & 12 \\
\hline & & Packaging 4 (Chunkybar) & 11.8 \\
\hline & & Packaging 5 (Ferrero rocher) & 14.5 \\
\hline & & Packaging 6 (Hershey's kisses) & 19.1 \\
\hline
\end{tabular}

The analysis of the sub-attributes showed that the sub-attribute of bitter taste had the highest priority weight in the taste attribute with a priority weight of $47.8 \%$. These results indicate that respondents prefer dark chocolate products with a bitter taste compared to chocolate with an acidic and astringent taste. The subattribute of cheap price had the highest priority weight in price attribute with a priority weight of $53.5 \%$. These results indicate that the respondents prefer cheap dark chocolate products to expensive ones. It is because most of the respondents are students $(42 \%)$ so that they choose useful products at low or affordable prices. The subattribute of nutritional benefit had the highest priority weight in the product benefit attribute with a priority weight of $38.2 \%$. These results indicate that respondents prefer dark chocolate products that have nutritional benefits to dark chocolate products that have health and psychological benefits. It means that respondents are aware of choosing dark chocolate products fortified with Spirulina platensis, which has nutritional benefits in meeting vitamin A needs [5]. However, the awareness of the respondents is still quite low compared to other sub-attributes, indicated by the high priority weight of other sub-attributes. The sub-attribute of sweet flavor had the highest priority weight on flavor attribute with priority weight of $64.2 \%$. These results indicate that respondents prefer dark chocolate products with a sweet flavor to dark chocolate products with a bitter and acidic flavor. Consumers prefer dark chocolate products with a slightly sweet taste generated by the presence of gum arabic and WPC ingredients used during the extraction process of Spirulina platensis nanocapsules. The sub-attribute of smooth texture had the highest priority weight in texture attributes, with a priority weight of $57.7 \%$. These results show that respondents liked smooth dark chocolate products better than rough and grainy ones. Consumers choose chocolate products that have a smooth texture (smooth and buttery), which can melt gently and slowly in the mouth with a complex and pleasant taste without leaving a hard impression [27]. The sub-attribute of typical chocolate aroma had the highest priority weight in the aroma attribute with a priority weight of $72.8 \%$. These results indicate that respondents prefer dark chocolate products with a distinctive aroma of chocolate to dark chocolate with fishy aroma. Fishy aromas are generated from Spirulina platensis that have a characteristic of fishy/green/grassy odor [8]. The sub-attribute of packaging 2 (Lindt) had the highest priority weight in the packaging attribute with a priority weight of $25.8 \%$. These results indicate that respondents prefer 
dark chocolate products with packaging such as packaging 2 (Lindt) over packaging 1 (Toblerone), packaging 3 (Silverqueen), packaging 4 (Chunkybar), packaging 5 (Ferrero rocher) and packaging 6 (Hershey's Kisses ).

\subsection{Consumer preference for dark chocolate products fortified with Spirulina platensis}

Consumer preference for dark chocolate products varies between one respondent and another respondent. Consumer preferences for dark chocolate products fortified with Spirulina platensis were analyzed using the Analytical Hierarchy Process method and processed with expert choice software. Analytical Hierarchy Process method is a method used to make decisions on complex problems such as planning problems, determining alternatives, setting priorities, and others. Problems faced by the AHP method can be said to be complex if the structure of the problem is inaccurate, so the input used to solve this problem is the human opinion [28].

Consumer preferences for dark chocolate products fortified with Spirulina platensis can be known from the respondents choosing the attributes of the dark chocolate products in the study. Dark chocolate product B (fortified with Spirulina platensis) had a priority weight of $55.8 \%$, while product A (without Spirulina platensis) had a priority weight of $44.2 \%$. The level of data inconsistency shows a value of 0.01 , indicating that the data are very consistent and valid. Therefore, it can be concluded that the consumer preferred dark chocolate products fortified with Spirulina platensis to dark chocolate products without Spirulina platensis. It is because dark chocolate fortified with Spirulina platensis has good nutritional content, especially pro-vitamin A nutrition. Dark chocolate fortified with Spirulina platensis has distinctive aroma of chocolate It also has taste and flavor which tend to be slightly sweeter compared to dark chocolate without Spirulina platensis, which is caused by the presence of gum arabic and WPC (Whey Protein Concentrate) as a material for making Spirulina platensis carotenoid nanocapsules. Moreover, dark chocolate fortified with Spirulina platensis also has price cheaper than the other.

\subsection{Weight recapitulation of two alternatives}

Dark chocolate product B (fortified with Spirulina platensis) had a priority weight of $55.8 \%$, while product A (without Spirulina platensis) had a priority weight of $44.2 \%$. The level of data inconsistency shows a value of 0.01 , indicating that the data are very consistent and valid. Dark chocolate products without Spirulina platensis have superior priority weights on flavor and aroma attributes, while dark chocolate products with Spirulina platensis have superior priority weights on texture, product benefits, price, packaging, and flavor attributes. Overall, the results of the comparison using the AHP method showed that the priority weight difference between dark chocolate products with and without spirulina was $11.6 \%$. The difference is quite big, meaning that the difference between the two products is quite significant.

\section{Conclusion}

Attributes are characteristics contained in a product that can affect consumer preferences. Attribute that influences consumer preferences for dark chocolate products is taste with sub-attribute of bitter taste $(47.8 \%)$, prices with sub-attribute of cheap price $(53.3 \%)$, product benefits with sub-attribute of nutritional benefits $(38.2 \%)$, flavor with sub-attribute of sweet flavor $(64.2 \%)$, texture with sub-attribute of smooth texture $(57.7 \%)$, aroma with sub-attribute of typical chocolate aroma (72.8\%) and packaging with sub-attribute of packaging 2 (Lindt) (25.8\%). Dark chocolate fortified with Spirulina platensis becomes a preference for consumers with a value of $55.8 \%$.

\section{References}

1. Budiardi, T. N.B.P. Utomo, A. Santosa. Jurnal Akuakultur Indonesia 9, 146-151 (2010)

2. Thomas, S.S. The Role of Parry Organic Spirulina in Health Management. Parry Nutraceuticals, Division of EID Parry (India) Ltd. India (2010)

3. Nuhu, A.A. Journal Marine Biology. 2013,1-8 (2013)

4. Chrismandha, T., Panggabean L.M. dan Mardiati Y. Berita Biologi. 8,163-169 (2006)

5. Christwardana, M., M.M.A. Nur \& Hadiyanto. Jurnal Aplikasi Teknologi Pangan Claresta 2,6-11 (2013).

6. Kusumawardhani, D. S. Skripsi. Fakultas Teknologi Pertanian. Universitas Gadjah Mada. Yogyakarta. Skripsi (2003) 
7. Risch, S. J., Encapsulation: Overview of Uses and Techniques. Di dalam S.J. Risch and G.A. Reineccius (Eds.). Encapsulation and Controlled Release of Food Ingredients. American Chemical Society. Washington DC. (1995)

8. Negara, H.P., I.Y.B. Lelana dan N. Ekantari. Jurnal Perikanan. 16,17-28 (2014)

9. Hamdan, A.B. Skripsi. Fakultas Pertanian UGM. Yogyakarta (2019).

10. Wijayanti, M.R. Skripsi. Universitas Sebelas Maret. Surakarta. 2011

11. Septiana, I. Skripsi. Institut Pertanian Bogor. 2010.

12. Pelsmaeker, S.D., J.J. Schouteten, S. Lagast, K.Dewettinck, X. Gellynck. Food Quality and Preferences. 62,323-664.(2017).

13. Akmaludin, A. dan Suryanto, S. 2016. Pengambilan Keputusan Dalam Pemilihan Notebook Berbasis Teknologi dengan Metode Multycriteria Decision Making (MCDM). 3,329-340 (2016).

14. Juliantoro, E. 2019. Skripsi. Fakultas Pertanian UGM. Yogakarta (2019).

15. Pujihastuti, I. Jurnal Agribisnis dan Pengembangan Wilayah. 2,43-56 (2010).

16. Saaty, T.L. International Journal Services Sciences. 1,83-98 (2008).

17. Sugiyono. Metode Penelitian Pendidikan. Alfabeta (2012).

18. Bramardian, B. Skripsi. Universitas Muhammadiyah Surakarta (2014)

19. Praseptiangga, D., Y. Nabila, D. R. A. Muhammad. Journal of Sustainable Agriculture. 33,78-88 (2018).

20. Ramlah, S. dan M. Yumas. Jurnal Industri Hasil Perkebunan. 12, 58-75 (2017).

21. Wahidin, Tamrin, \& E. Danggi. Jurnal Sains dan Teknologi Pangan. 2,285-297 (2017).

22. Nawawi, I. Islam dan Bisnis. VIV Press. Surabaya (2011).

23. Sulistiyono. Skripsi. (2011)

24. Cahyorini, A. dan E.Z. Rusfian. Journal of Administrative Science and Organization. 18,11-21 (2011).

25. Nur'aeni, M.D.R. Skripsi. 2016.

26. Pratama, R.I., I. Rostini dan M.Y. Awaluddin. Jurnal Akuatika. 4,55-67 (2013)

27. Rahmawati, F. Skripsi. Universitas Pasundan. Bandung. (2016)

28. Saaty, T.L. The Analytic Hierarchy Process. McGraw-Hill. New York. (1980) 